\title{
Investigation of Rectifier Circuit Configurations for Microwave Power Transmission System Operating at S Band
}

\author{
Doan Huu Chuc*, Bach Gia Duong** \\ * Department of Electrical and Electronics, Hai Phong Private University \\ ** Department of Electronics and Telecommunications, VNU University of Engineering and Technology
}

\begin{tabular}{l}
\hline Article Info \\
\hline Article history: \\
Received Feb 10, 2015 \\
Revised May 14, 2015 \\
Accepted Jun 10, 2015 \\
\hline
\end{tabular}

Keyword:

Conversion efficiency

HSMS2820

Microwave power transmission

Rectifier

Wireless power transmission

\begin{abstract}
The purpose of this work is to propose rectifier circuit topologies for microwave power transmission system operating at ISM band. This paper particularly presents in detail the proposed rectifier circuit configurations including series diode half wave rectifier and voltage doubler rectifier. The maximum conversion efficiency of rectifier using series diode half wave rectifier is $40.17 \%$ with $220 \Omega$ load resistance whereas it is $70.06 \%$ with $330 \Omega$ load resistance for voltage doubler rectifier. Compared to the series rectifier circuit, it is significant to note that the voltage doubler rectifier circuit has higher efficiency. The circuits presented are tuned for a center frequency of $2.45 \mathrm{GHz}$. The rectifiers were fabricated using microstrip technology. The design, fabrication and measurement results were obtained using a well-known professional design software for microwave engineering, Advanced Design System 2009 (ADS 2009). All design and measurement results will be reported.
\end{abstract}

Copyright (C) 2015 Institute of Advanced Engineering and Science. All rights reserved.

\section{Corresponding Author:}

Doan Huu Chuc,

Department of Electrical and Electronics,

Hai Phong Private University,

36 Dan Lap Road, Le Chan Dist, Hai Phong City, Vietnam

Email: chucdh@hpu.edu.vn

\section{INTRODUCTION}

Microwave power transmission (MPT) is one of the hot topics in microwave and millimeter wave devices, circuit, and systems. Microwave power transmission has had a long history before the more recent movement toward wireless power transmission (WPT). MPT research has been driven primarily by the desire to remotely power unmanned aerial vehicles (UAVs) and by the concept of space solar power (SPS) first by Dr. Peter Glaser of the Arthur D. Little Company in 1968 [1]. MPT can be applied not only to beam type point to point WPT but also to an energy harvesting system fed from distributed or broadcasting radio waves. A rectifying antenna (Rectenna), which is used to convert the microwave power to the direct current (DC) power, is one of the key components of the MPT system. A rectenna is a passive element with rectifying diodes that operates without an internal power source. It can receive and rectify microwave power to DC power [2]-[5]. A general block diagram of a conventional rectenna is shown in Figure 1. Rectenna mainly consists of a receiving antenna, low pass filter, rectifying circuit (rectifier) and output filter (DC filter). The output voltage of rectenna is fed to load resistance.

We can apply various antennas and rectifying circuits. The selection depends on requirements for the systems and its users. When we use a rectenna array, the antennas in the rectennas can absorb $100 \%$ of input microwaves. Higher efficiency rectifying circuits are required because the MPT system is an energy system. There are various rectifying circuits that can reach $100 \%$ efficiency in theory [6].

Working frequency is also an important parameter to consider when designing a rectenna. It is often dictated by the desired application. At low frequencies (below 1GHz), high gain antennas tend to be quite 
large. Increasing the frequency thus allows the use of more compact antennas. On the other hand, the amount of available power at a certain distance from an emitter is given by Friis equation [6-8].

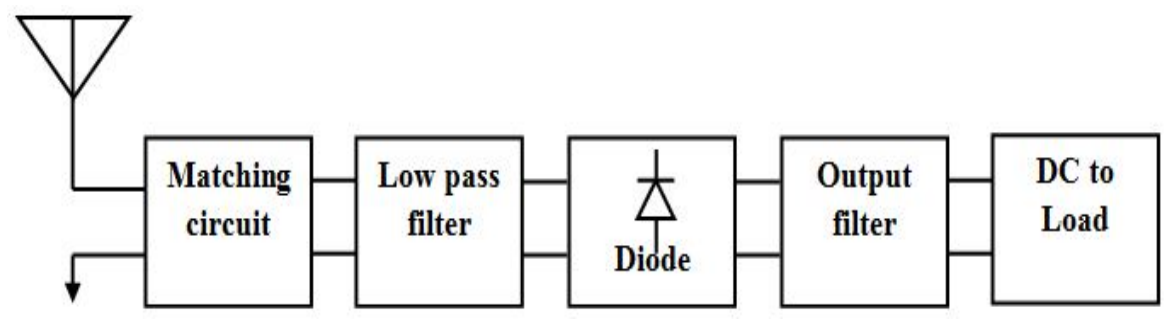

Figure 1. Block diagram of rectenna.

$$
P_{r}=P_{t} \cdot G_{t} \cdot G_{r} \cdot\left(\frac{\lambda}{4 \pi R}\right)^{2}
$$

Where $P_{t}$ is the power of the emitter, $G_{t}$ and $G_{r}$ are the emitter and receiver antenna gain respectively, $\lambda$ is the wavelength used and $\mathrm{R}$ is the distance separating the emitter and the receiver. This means that available power at a certain distance from the emitter decreases as the frequency increases. Frequencies in the $1 \mathrm{GHz}-3 \mathrm{GHz}$ range are considered to provide a good compromise between free space attenuation and antenna dimensions. In this paper, we focused on the microwave capture and conversion in the ISM (Industrial Scientific Medical) band at $2.45 \mathrm{GHz}$.

Rectifier is a nonlinear circuit, which converts RF power into DC power. The mathematical relation that describes the conversion efficiency is given by (2) [6].

$$
\eta_{\text {rec }}=\left(\frac{\mathrm{P}_{\mathrm{DC}}}{\mathrm{P}_{\mathrm{r}}}\right)=\frac{\mathrm{V}_{\mathrm{R}_{\mathrm{L}}}^{2} / \mathrm{R}_{\mathrm{L}}}{\mathrm{P}_{\mathrm{r}}}
$$

Where $V_{R}(V)$ is the output voltage drop across the load, $R_{L}(\Omega)$ is the load value, $P_{r}$ is the RF input power at the receiving antenna's output port, and $\mathrm{P}_{\mathrm{DC}}$ is the DC power entering at the load $\mathrm{R}_{\mathrm{L}}$.

In general, a rectifier consists of a rectifying diode, an input and output matching networks, a band pass or low pass filter, and a DC filter. The output DC filter is often constituted by a lumped shunt capacitor, a distributed microstrip low pass filter or a radial stub. The microwave-to-DC rectifier can take several configurations. The single series and shunt diode half wave rectifier circuit configurations are the most popular. The voltage doubler topologies can be used so as to enhance the output DC voltage[9].

In [5], the authors propose an ISM band rectenna operating at $2.45 \mathrm{GHz}$. It consists of a circular microstrip patch antenna and a series diode half wave rectifier. The maximum microwave-to-DC conversion efficiency in this configuration is $34 \%$ at $-10 \mathrm{dBm}$ of the RF incident upon the diode.

The four microwave rectifier circuits are reported in [9]. The rectifier configurations are single series, shunt diode, voltage doubler and Villard voltage doubler. The highest conversion efficiency is $56.6 \%$. In [10], the paper shows all the activities addressed to design a wideband system to recover wideband energy from electromagnetic sources present in the environment for wireless sensor node. RF-DC conversion efficiency reaches $37 \%$.

In this paper, we are presenting the design, simulation and fabrication of two rectifier circuit topologies for microwave power transmission operating at $\mathrm{S}$ band. The first part of this paper presents several design challenges of rectifier circuit. Fabrication and measurement of the proposed rectifier models are presented in the subsequent parts. The printed circuit board (PCB) technology is used to minimize the circuit size and losses. Finally, conclusions and future work of this research are discussed.

\section{RECTIFIER CIRCUIT CONFIGURATIONS}

\subsection{Series Diode Half Wave Rectifier}

Series diode half wave rectifier is made up of a diode and a capacitor. The rectifier blocks the negative half cycle [9]. The basic structure of a series diode half wave rectifier is shown in Figure 2. The 
input impedance match network consists of microstrip lines TL1, TL2 and short stub TL3 working at Sband. The choice of diodes plays an important role in the power conversion circuit. Accordingly, the diode must have low reverse recovery time and the conversion efficiency must be high [11]. Schottky diode HSMS2820 is chosen as conversion device for the design of rectenna system in the research. It has the equivalent circuit parameters as follows, series resistance $\mathrm{R}_{\mathrm{S}}=6 \Omega$, zero bias junction capacitor $\mathrm{Cj}_{0}=0.7 \mathrm{pF}$, forward voltage $\mathrm{V}_{\mathrm{F}}=0.34 \mathrm{~V}$, and breakdown voltage $\mathrm{V}_{\mathrm{B}}=15 \mathrm{~V}$. The output filter is composed of a chip capacitor and a quarter-wavelength transmission line $\lambda / 4$, which smoothes the DC voltage and reutilizes harmonics energy [12]-[14]. Since the diode is connected in series, the harmonic waves are directly reflected back, and then they are re-rectified by the diode. The DC power is collected by a load resistance. The circuit is simulated in double sided FR4 (Dielectric constant $=4.34$, Height $=1.6 \mathrm{~mm}$, Thickness $=0.035 \mathrm{~mm}$ ).

Rectifier circuits have a highly nonlinear behavior mostly because of the diode rectification process. It is not practical to design sub parts separately because they highly interact with each other. The load of the input filter depends on the diode and the output filter. For this reason, a global circuit optimization technique must be used for dimensioning the passive components of the filter elements [6]. These optimizations were made with the software ADS from Agilent Technologies. The ADS is chosen because of its excellence features such as flexibility in schematic and layout editing and time efficient simulation. The detail parameters of Schottky diodes that are used in both rectifier circuits can be obtained directly from the component library in ADS [9].

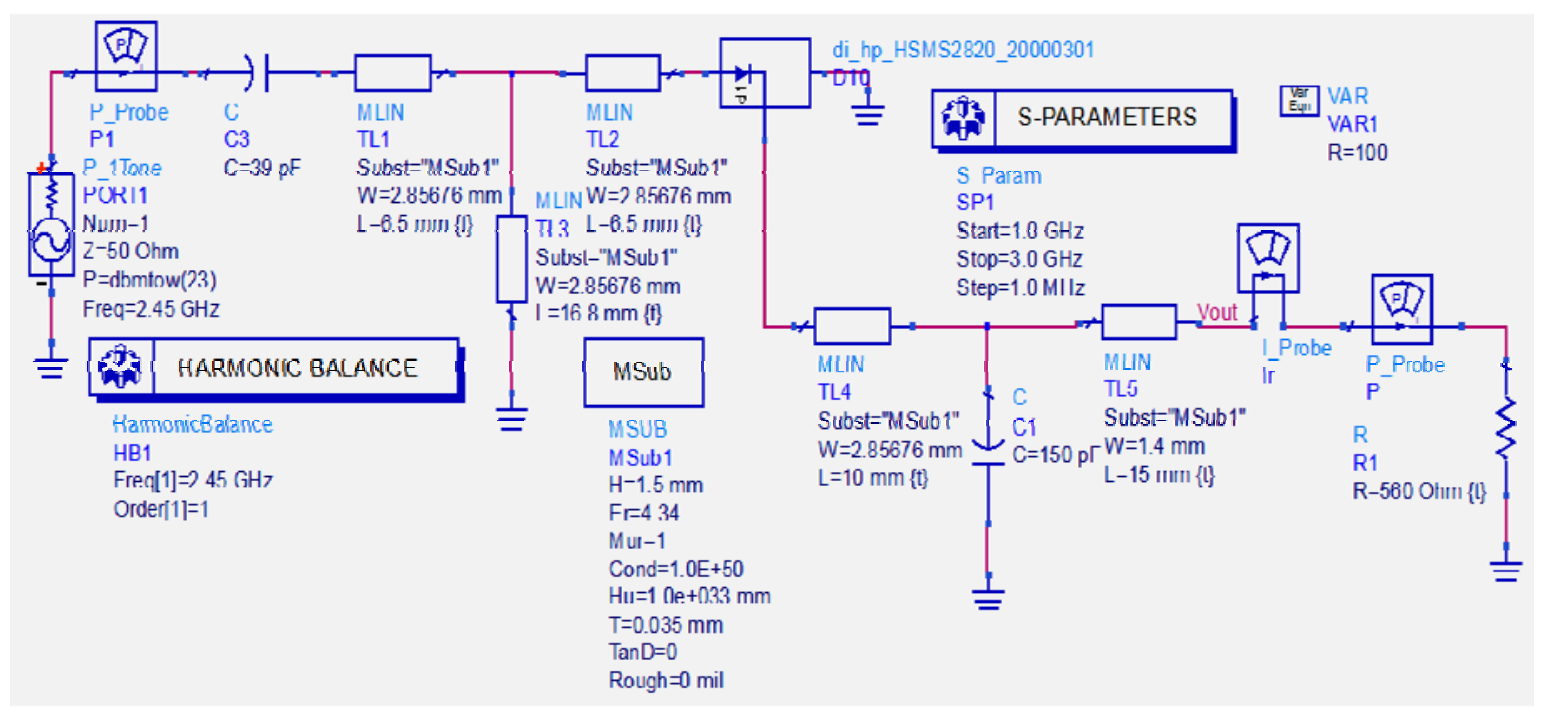

Figure 2. The schematic of the series diode half wave rectifier

Our design is exported in terms of layout and fabricated by mean of LPFK Protomat - C40. The layout dimension of the rectifier system is $4.2 \mathrm{~cm} \times 2.4 \mathrm{~cm}$. It was fabricated using FR4 substrate. The fabrication of the series diode half wave rectifier is illustrated in Figure 3.

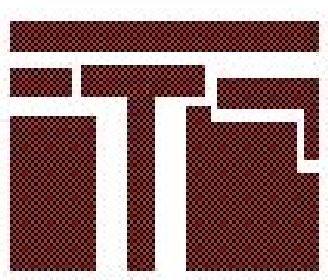

(a)

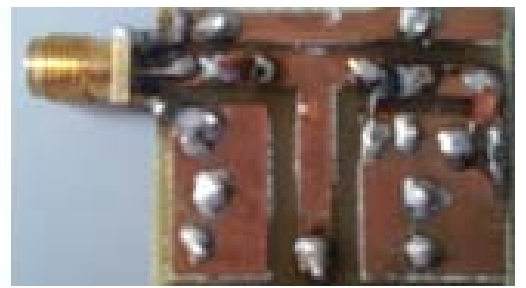

(b)

Figure 3. Layout (a) and Fabrication (b) of Series diode half wave rectifier 
The microwave signal generator Aligent $8648 \mathrm{C}$ is used as the microwave source for the power amplifier using E-pHEMT MMG20271H. The DC voltage $\mathrm{V}_{\mathrm{RL}}$ on the load $\mathrm{R}_{\mathrm{L}}$ is measured by a voltage meter. With the series diode half wave rectifier, it has been found in the experiment that this rectifying circuit has the DC voltage of $5.7 \mathrm{~V}$ at $2.45 \mathrm{GHz}$ with the load resistance of $220 \Omega$ when input power level is $26 \mathrm{dBm}$ (the maximum power level of the power amplifier MMG20271H). The output voltage and the measured RFDC conversion efficiency of the series rectifier are shown in Figure 4.

The highest conversion efficiency reaches $40.17 \%$ with the load resistance of $220 \Omega$ at the input power of $24 \mathrm{dBm}$. The conversion efficiency increases gradually with the input power when the input power is less than $24 \mathrm{dBm}$. The efficiency drops when the input power is more than $24 \mathrm{dBm}$. Between $22 \mathrm{dBm}$ and $25 \mathrm{dBm}$ input power, the efficiency exceeds 37\%. The DC output voltage is $2.85 \mathrm{~V} @ 20 \mathrm{dBm}, 4.2 \mathrm{~V} @ 23$ $\mathrm{dBm}$ and reaches $5.7 \mathrm{~V} @ 26 \mathrm{dBm}$ input power respectively. For practical applications, the antenna and rectifier circuit can be integrated directly on one substrate by omitting SMA connectors. Eliminating the loss of SMAs, the microwave to DC conversion efficiency can be higher.

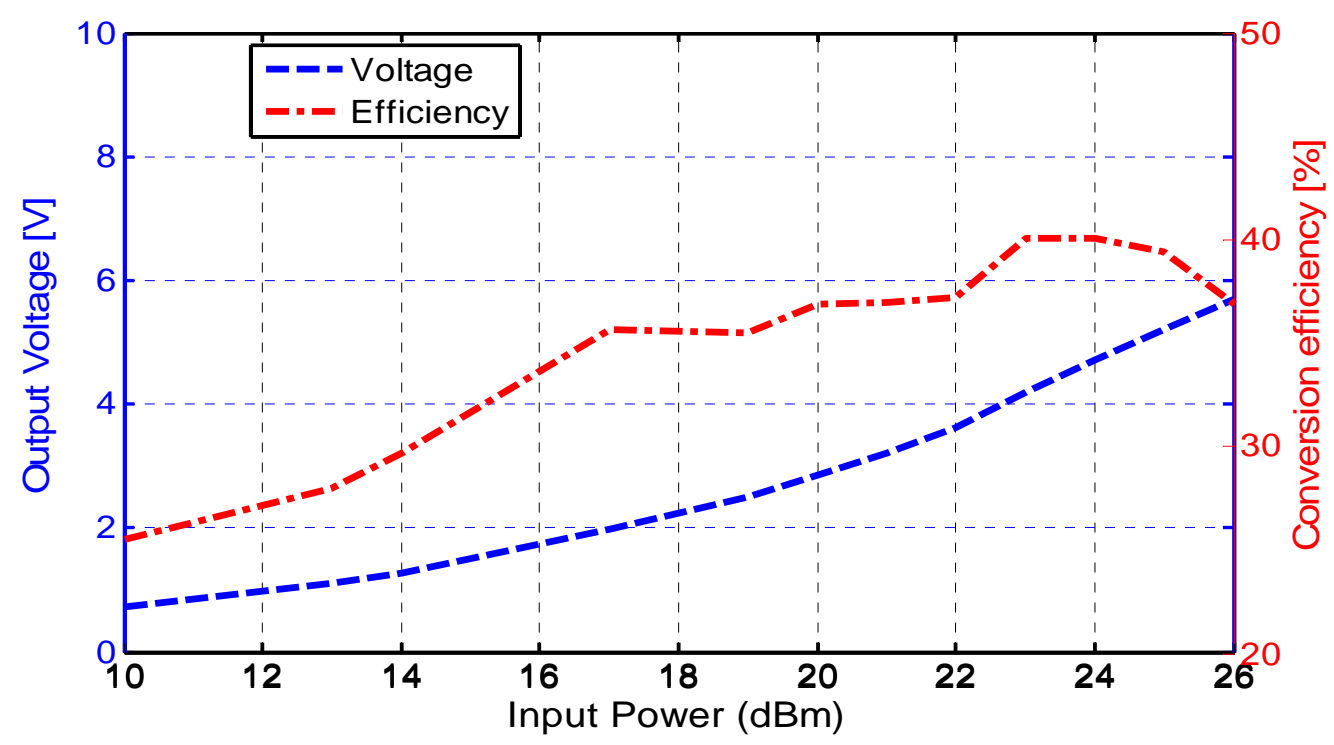

Figure 4. The output voltage and measured conversion efficiency of Series diode half wave rectifier

\subsection{Voltage Doubler Rectifier}

The voltage doubler rectifier (VDR) is an amplitude amplifying circuit that uses dual diodes. The voltage doubler rectifier is composed of a peak rectifier formed by diode D1 and capacitor C1 and a voltage clamp formed by diode D2 and capacitor C2 [6]. A dual diodes voltage doubler with only single capacitor is unpopular but the VDR is a well defined single stage voltage doubler that doubling the amplitude of input signals. In our design a HSMS2820 Schottky diode was also used in voltage doubler rectifier, and has a voltage drop of $340 \mathrm{mV}$. This low voltage drop provides high switching speed and better system efficiency. The schematic of a VDR is shown in Figure 5. The microstrip lines required for efficient charging and impedance transformation are shorter as compared to the other configurations. As a result, this configuration has the potential to allocate smaller footprint. The merit of smaller form factor is significant because multiple rectifiers are essential in rectenna array. In this circuit, the microstrip line TL2 is used for input matching and the microstrip line TL3 is used for output matching. The circuit was designed, simulated and optimized using Advance Design System (ADS), then it was fabricated on FR4 substrate for verification. 


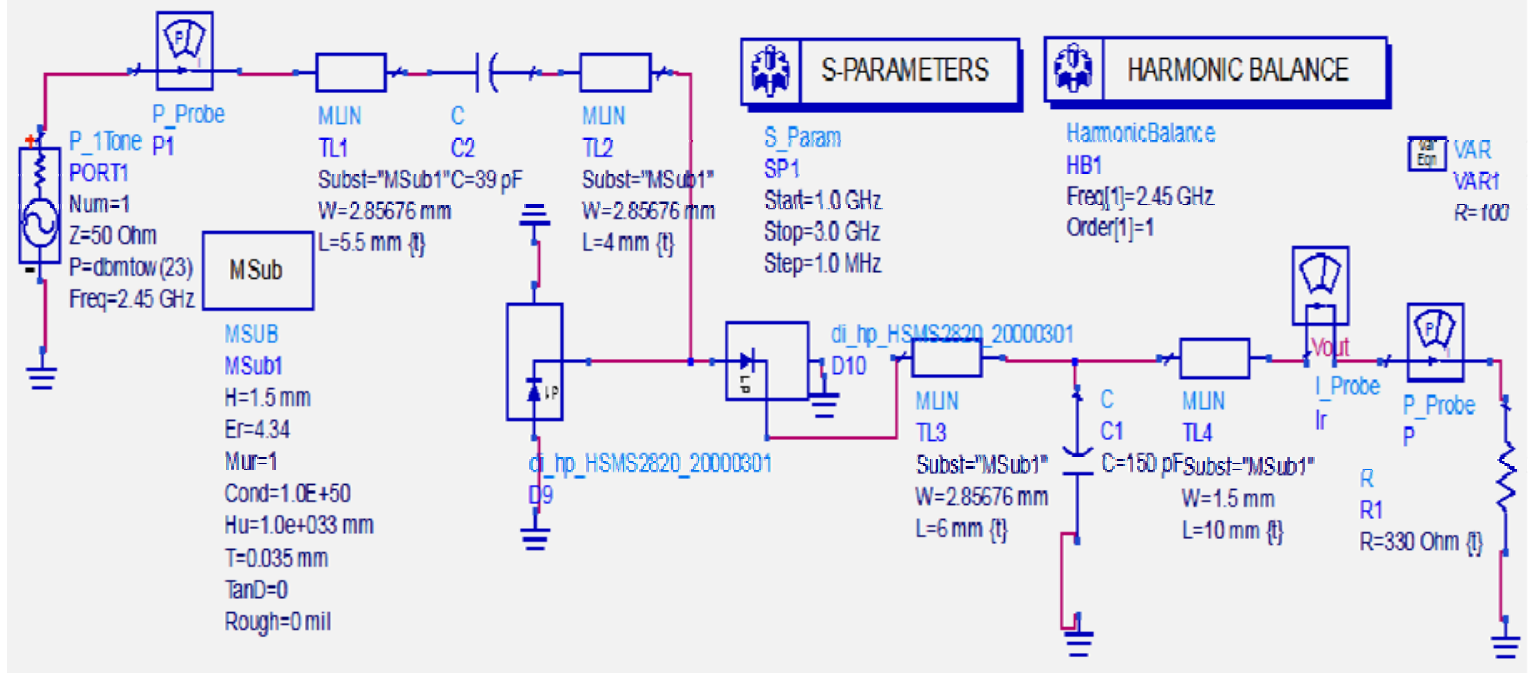

Figure 5. The schematic of the voltage doubler rectifier

The layout and fabrication of the voltage doubler rectifier are shown in Figure 6. The dimension of the rectifier system is $4 \mathrm{~cm} \times 1.4 \mathrm{~cm}$. The PCB (Printed Circuit Board) was manufactured by a computercontrolled machine LPFK Protomat - C40. Compared to the series diode half wave rectifier, the size of the voltage double rectifier is smaller.
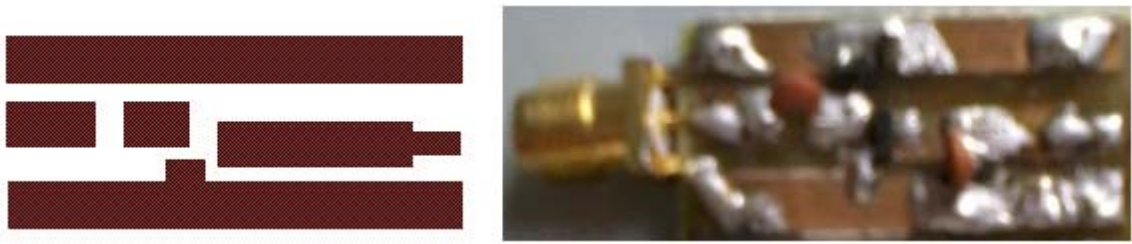

Figure 6. The layout and fabrication of the voltage doubler rectifier

The conversion efficiency is measured with respect to the rectifier load at range of $10 \mathrm{dBm}$ to 26 $\mathrm{dBm}$ of input power. The optimal load resistance is around $330 \Omega$ for $+23 \mathrm{dBm}$ input power at the frequency of $2.45 \mathrm{GHz}$. The measured efficiency values are plotted in Figure 7. Accordingly, the maximum conversion efficiency of $70.06 \%$ is reached at $23 \mathrm{dBm}$ of input power. From Figure 7, as can be seen that the conversion efficiency increases until the input power reaches $23 \mathrm{dBm}$, then conversion efficiency decreases rapidly. Between $16 \mathrm{dBm}$ and $25 \mathrm{dBm}$ input power, the conversion efficiency exceeds $60 \%$. The DC voltage output level is 4.75 V@20 dBm,6.8 V@23 dBm and 8.7V@26 dBm input power respectively. For practical applications, the antenna and rectifier circuit can be integrated directly on one substrate omitting SMA connectors. Without the loss of SMAs, the microwave to DC conversion efficiency can be higher. 


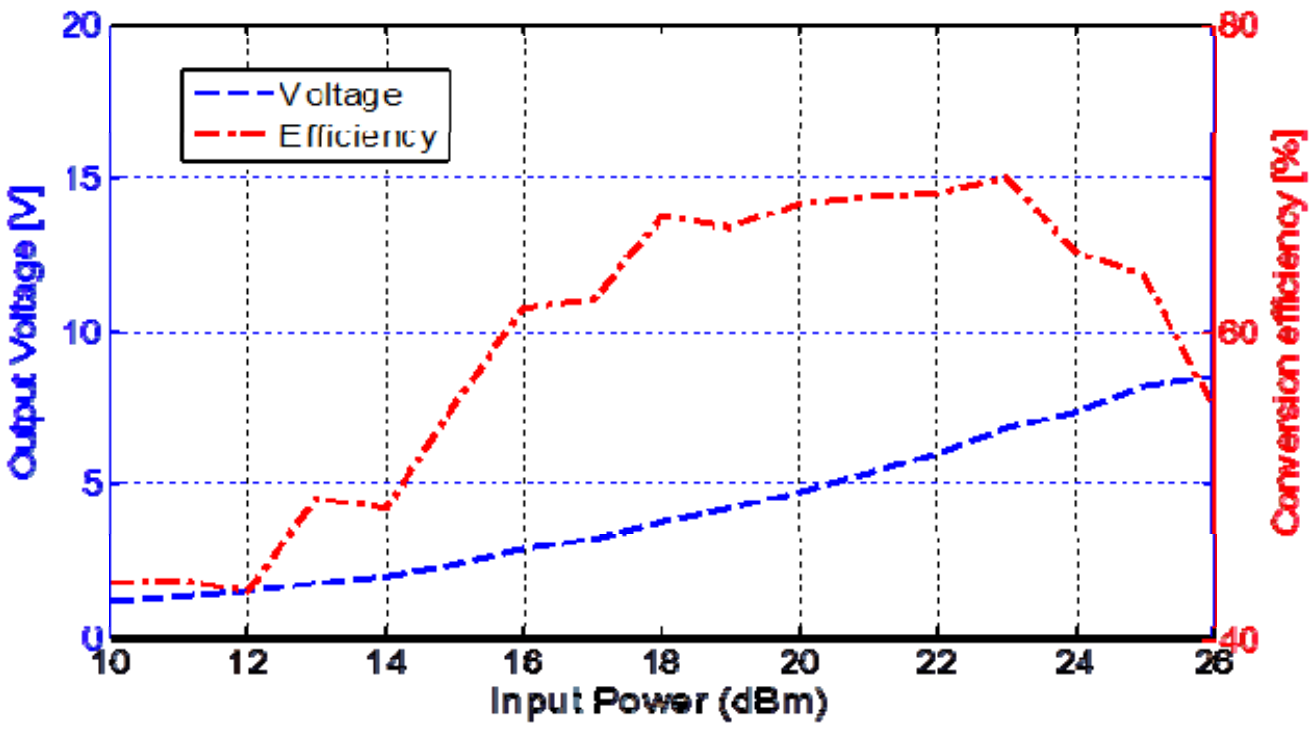

Figure 7. Measured DC voltage and conversion efficiency of the voltage doubler rectifier

Figure 8 shows the measured conversion efficiency as a function of load resistance with respect to different input powers. Accordingly, the measured rectifying efficiency is higher than 54\% when the load resistance is between $150 \mathrm{Ohm}$ to $560 \mathrm{Ohm}$. The maximum DC output voltage is $11 \mathrm{~V}$ with $560 \mathrm{Ohm}$ load resistance, the efficiency reaches $54.3 \%$. The highest efficiency attains $70.6 \%$ with 330 Ohm load resistance. The conversion efficiency also increases when the input power is less than $24 \mathrm{dBm}$. Then the conversion efficiency drops rapidly when the input power is more than $24 \mathrm{dBm}$ because the diode voltage has exceeded the breakdown voltage. As can be seen that the optimal load resistance is around $330 \Omega$ for all input power levels at the frequency of $2.45 \mathrm{GHz}$. Compared to the series diode half wave rectifier, the VDR has higher conversion efficiency as can be seen in Figure 7 and Figure 8. From this analysis, we conclude that the voltage doubler rectifier has better performance compared to the series diode half rectifier.

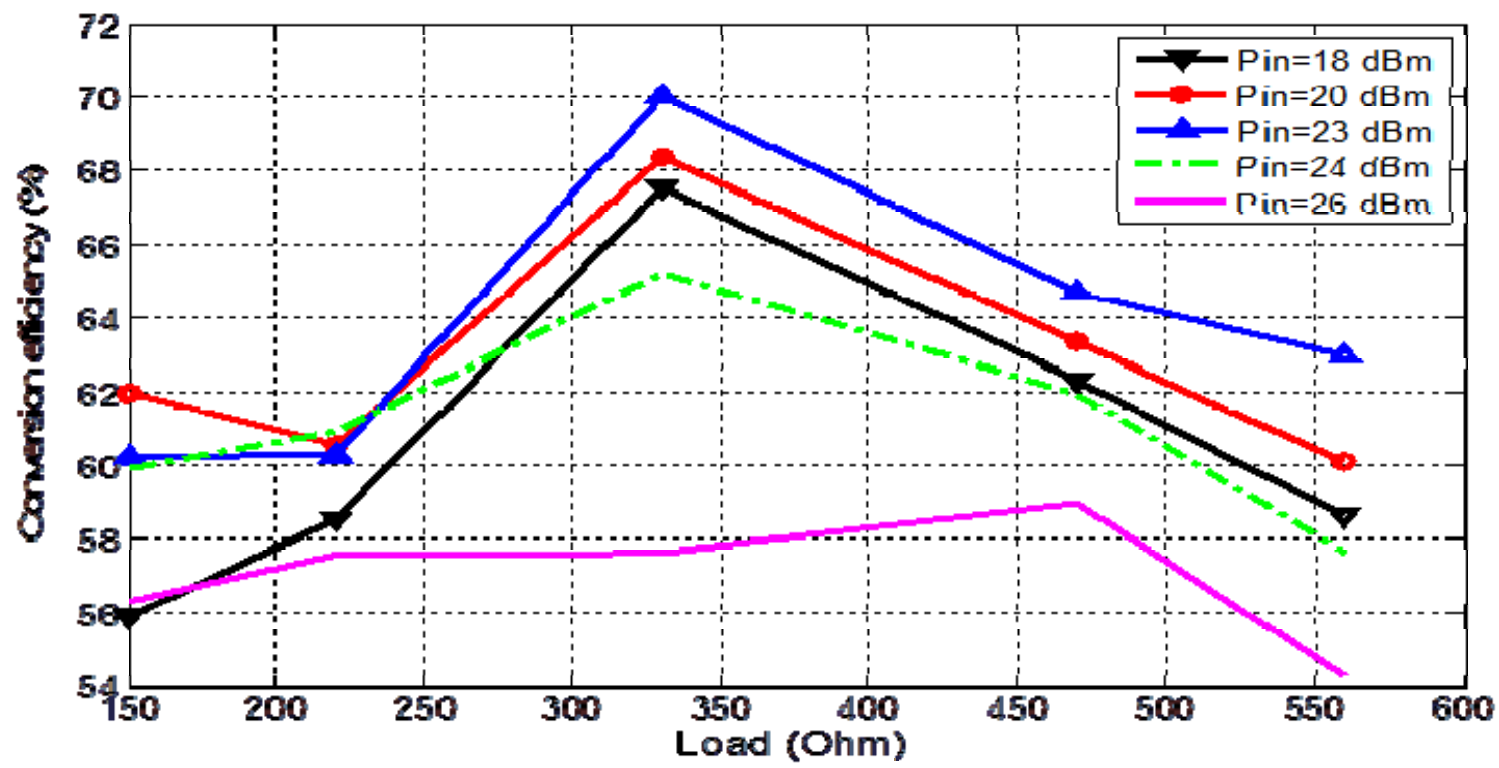

Figure 8. Measured conversion efficiency versus load resistances 


\section{CONCLUSION}

A rectifier is one of the key technologies for microwave power transmission and energy harvesting. Series diodes half wave and voltage double rectifier circuit configurations have been researched, designed and measured for different load resistances. Good performances have been obtained in terms of microwaveto-DC conversion efficiency. The measured conversion efficiency of voltage doubler rectifier is over $70 \%$. The proposed rectifier circuits can be used for microwave power transmission systems applications. For future work, the objective is to increase the rectifier performance in term of microwave - to - DC conversion efficiency.

\section{ACKNOWLEDGEMENTS} QG.15.27.

This work has been sponsored by Vietnam National University, Hanoi (VNU), under Project No.

\section{REFERENCES}

[1] Bernd Strassner and Kai Chang, "Microwave Power Transmission: Historical Milestines and System Components", Proceedings of the IEEE, Vol. 101, No. 6, pp. 1379-1396, June 2013.

[2] N. Shinohara, "Rectennas for microwave power transmission", IEICE Electronics Express, vol. 10, No. 21, November 2013

[3] Duan Zhao, Enjie Ding and Xin Wang, "Multiple-Input Single-Output Wireless Power Transmission System for Coal Mine", TELKOMNIKA Indonesian Journal of Electrical Engineering, Vol. 12 No. 6, pp 4572-4578, 2014.

[4] Duan Zhao, Enjie Ding and Xin Wang, "Design and Simulation of Multiple Coil Model for Wireless Power Transmission System", TELKOMNIKA Indonesian Journal of Electrical Engineering, Vol. 12 No. 6, pp. 41664177, 2014.

[5] Mohamed Louzazni, El Hassan Aroudam, Hanane Yatimi, "Modeling and Simulation of A Solar Power Source for a Clean Energy without Pollution", International Journal of Electrical and Computer Engineering (IJECE), Vol. 3, No. 4, August 2013.

[6] S. Riviere, et al., "A compact rectenna devide at low power", Progress In Electromagnetics Research C, vol.16, pp.137-146, 2010

[7] A. Adya Pramudita, Lydia Sari, V. Windha Mahyastuti, "Experimental Study on Increasing the Received Power of Antenna using Circularly-Polarized Array Antenna", International Journal of Electrical and Computer Engineering (IJECE), Vol. 2, No. 2, 2012

[8] Y.Y. Gao, X.X. Yang, C. Jiang, and J.Y. Zhou, "A circularly polarized rectenna with low profile for wireless power transmission", Progress In Electromagnetics Research Letters, vol. 43, pp. 41-49, 2013.

[9] Wai Siang, Yeoh, "Wireless power transmission (WPT) application at $2.4 \mathrm{GHz}$ in common network", RMIT University, Doctor of Philosophy's Thesis, March 2010.

[10] D. Pavone, et al, "Design considerations for radio frequency energy harvesting devices", Progress In Electromagnetics Research B, Vol. 45, pp. 19-35, 2012.

[11] K. Chaudhary, Babau R. Vishvakarma, "Comparative study of rectenna configurations for Satellite solar power station”, IPCSIT, IACSIT Press, vol. 7, pp. 73-77, Singapore, 2011.

[12] Zied Harouni, Lotfi Osmanand and Ali Gharsallah, "Efficient $2.45 \mathrm{GHz}$ Rectenna Design with High Harmonic Rejection for Wireless Power Transmission", IJCSI International Journal of Computer Science Issues, Vol. 7, Issue 5, pp. 424-427, September 2010.

[13] V. Marian, C. Vollaire, B. Allard, J. Verdier, "Low power rectenna topologies for medium range wireless energy transfer", Proc. 14th EPE 2011, pp. 1-10, Birmingham, UK, Aug 2011.

[14] Changjun Liu, et al, "Study on an S - band rectenna array for wireless microwave power transmission", Progress In Electromagnetics Research, vol. 135, pp. 747-758, 2013.

\section{BIOGRAPHIES OF AUTHORS}

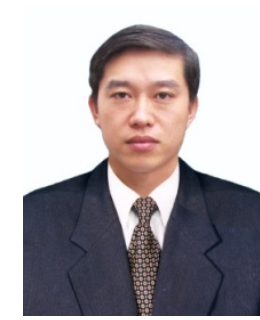

Doan Huu Chuc was born in Hai Phong City, Vietnam, in 1978. He received the B.S. and M.S. degrees in engineering electronics from the Vietnam National University (VNU), Hanoi in 2000 and 2007, respectively. He is a Lecturer of Department of Electrical and Electronics, Hai Phong Private University. He is currently pursuing the Ph.D. degree in electronic engineering at VNU, where his dissertation is focused on microwave circuit designs for wireless power transmission and high power semiconductor amplifiers.

Email: chucdh@hpu.edu.vn 


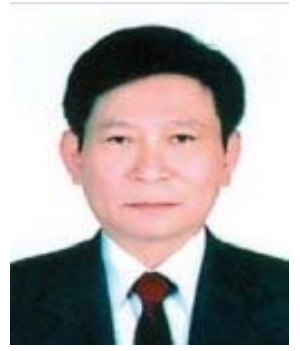

Assoc. Prof. Bach Gia Duong was born in Ha Dong Dist, Hanoi, Viet Nam, in 1950. He received the B.S degree in radio physics in 1972 and the Ph.D. degree in wireless physics from University of Science, in 1988. Since 2006, he is a Lecturer and Head of Electronics and Telecommunication Center, University of Engineering and Technology, Vietnam National University. He is the author of three books and more than 80 articles. His research focuses on RF Analog Signal Processing, RF chip design, Radar Engineering and Technology, Automatic Control.

Email: duongbg@vnu.edu.vn 